\title{
Reasonable disagreement and the justification of pre-emptive ethics governance in social research: A response to Hammersley
}

To cite: Sheehan, M., Dunn, M. and Sahan, K. (2018) 'Reasonable disagreement and the justification of pre-emptive ethics governance in social research: A response to Hammersley', Journal of Medical

Ethics, 44(10): 719-720.

\begin{abstract}
In this response, we first tackle what we take to be the core disagreement between ourselves and Hammersley, namely the justification for our model of social research ethics governance. We then consider what follows from our defence of governance for ethics review and show how these claims attend to the specific concerns outlined by Hammersley.
\end{abstract}

Text

We are grateful to Martyn Hammersley for his response ${ }^{1}$ to our paper. ${ }^{2}$ In particular, we appreciate the extent to which his arguments are in many important respects directly in line with the concerns and claims that we advance. Hammersley does not comment on our core argument about the nature of the stake that society has in research, which we advanced in order to ground a general claim for social research ethics governance. However, we recognise Hammersley agrees with us that social research is the kind of activity that should be subject to governance, even if we disagree about the nature of the governance arrangements.

In what follows below we first tackle what we take to be the core disagreement between ourselves and Hammersley, namely the justification for our model of social research ethics governance. We then consider what follows from our defence of governance for ethics review and show how these claims attend to the specific concerns outlined by Hammersley.

One of the central points of our position is the idea that a system of governance must recognise that there are a range of ethical considerations (reflecting different values or perspectives) relevant to considering the acceptability of research about which people can reasonably disagree, and in the context of which decisions need to be made. Crucially, in order for a system of governance to be justified it cannot, in principle, privilege some values over others - this means that decisions about the ethical acceptability of research should be free of exaggerated values, concerns or perspectives.

This point goes to the heart of Hammersley's worries about moralism and about a system that gives excessive weight to one consideration over others. We share this concern and we have argued for an account of governance that rests precisely on meeting this worry. Our account relies on a case-bycase decision-making process that is publicly accountable in the context of reasonable disagreement about the ethical acceptability of the proposed research. 
In contrast, Hammersley claims that "the process of mandatory, pre-emptive ethics regulation by its very nature tends to give too much weight to certain ethical considerations" ( $p . X X X)$. We find it hard to see how such a system could by its very nature be skewed towards moralistic judgements, particularly since our account of how this system ought to function is, by its very nature, set up precisely not to be skewed in this way. The clue here is Hammersley's own view. For Hammersley, the appropriate form of social research governance is to allow the researcher to judge the acceptability of their research, with retrospective sanctions being applied on the researcher, rather than a properly constituted, publicly accountable research ethics committee.

Hammersley advances this position because what primarily matters for the ethical justification of research is that the research aims to produce, what Hammersley and Traianou ${ }^{3}$ call, 'value-relevant knowledge': knowledge produced within research that is valuable as knowledge. Hammersley and Traianou recognise, however, that this internal value of research must be balanced against extrinsic values that are weighted appropriately. They identify harm minimisation, respect for participant autonomy and the protection of privacy as examples of such extrinsic values. But, on this account, it is the researcher, as an autonomous professional dedicated to the task of research, who is best placed to determine how far these external constraints apply. For example, the researcher is to judge when the harm in a particular case has been minimised enough relative to the production of value-relevant knowledge, or when the autonomy of a particular set of participants will have been adequately respected relative to the value of the knowledge that stands to be produced.

Our view is that it is far from clear that the researcher will be best placed to balance these values appropriately. The researcher will hopefully be heavily invested in the research, in precisely the ways that Hammersley and Traianou describe, being deeply committed to the production of 'valuerelevant knowledge'. Leaving the requirement to weigh up ethical constraints to the production of knowledge raises the distinct possibility of moralism slipping back in. Indeed, Hammersley's account - with its privileging of knowledge production over all other considerations - looks precisely to permit social researchers to give exaggerated (and so illegitimate) weight to one ethical consideration over others, in ways that reflect their normative commitments as academic social scientists.

Notwithstanding these potential problematic implications of Hammersley's view, there is an even stronger reason against the researcher being tasked with making the judgement about whether the research should be allowed to proceed. This is because it would be unacceptable, in principle, to those who reasonably disagree with the judgement made by the researcher, that the researcher should be accorded the authority to make this decision. The justification of any system of social research ethics governance turns on this latter point: what matters (and what ensures that the process does not in principle exaggerate some values over others) is its acceptability to those who reasonably disagree about how the different ethical values relevant to making a well-reasoned judgement about the acceptability of a piece of research should be balanced.

We move now to consider what follows from our defence of a particular governance model for social research and consider its implications for Hammersley's more specific objections to our arguments.

First, building on the points discussed above, we recognise Hammersley's concern about the moralising tendencies of research ethics committees. We agree that there is significant anecdotal evidence that committee members (or committees as a whole) tend to bring particular ethical bugbears to their work on the committee, and that this can lead to an over-weighting of one or more ethical considerations, such as the requirement to respect participants' autonomy. We also 
recognise that such tendencies can lead to an inappropriate narrowing of ethical deliberations, and give rise to indefensible judgements about whether a piece of research should be allowed to proceed or not. However, as we claimed above, the model of governance that we proposed is explicitly designed to address such concerns. By founding social research ethics review on the view that normative legitimacy is secured by putting in place a just procedure, those participating in the ethics review process are required to make transparent and accountable decisions in ways that clearly articulate precisely how relevant ethical trade-offs have been made on a case-by-case basis.

Second, Hammersley takes us to task for our failure to represent Dingwall's observations about harm in social research correctly. It is indeed accurate to point out that we did not take it upon ourselves to give a full typology of harms in research of this kind. As Hammersley notes, such effort has been put to good use elsewhere. ${ }^{4}$ We recognise that Dingwall makes the (accurate) claim that most social research carries a low likelihood of serious harm, when compared to medical research. ${ }^{5}$ But, we think it is important to point out that nothing follows from this observation for the justification of social research ethics governance. This is because the precise relevance to the ethics review process of the degree of harm (of even a potentially small and limited kind) in a social research study will depend on how this ethical consideration is to be reasonably weighed against other countervailing ethical considerations, in light of the specific aims and methods of the study being reviewed.

We also note that this exercise in ethical judgement will require subtle interpretation of the facts about the harms that it can be reasonably foreseen will arise in a study. It is entirely feasible to think that social researchers' perceptions of the harms that arise through participation in a particular research methodology might differ markedly from how participants in the research actually experience the harms and benefits of participation. Thus, asserting an over-arching claim about the existence of agreement between social scientists about the degree and types of harms that arise within social research is likely to be unconvincing.

Finally, Hammersley accuses us of failing to address concerns about (the lack of) ethical expertise in research ethics review. Here, we wish to correct a misunderstanding of our claims, and to clarify why this objection has no force. Justifying social research ethics governance by recourse to a fair process model of ethical decision-making takes the question of ethical expertise out of the equation entirely. On our account, the committee operates legitimately by adhering to the procedural requirements of an adapted 'accountability for reasonableness' framework. Importantly, in so far as the committee members operate within this framework, there is no distinctive ethical expertise relevant to the justification or practice of ethics review that exists independently of this process. In this sense, it is the decision-making process which is authoritative, not the committee. Indeed, we would go so far as to say that any committee member, or social researcher, who put themselves forward as an ethics expert in this context would be at great risk of undermining the legitimacy of a fair process model of research ethics governance. Once again, this would be due to the clear possibility that such ethical expertise might be advanced in the committee setting to make assertions about overarching or exaggerated ethical values that opened the door to indefensible (and moralistic) judgements about the research in question.

Notwithstanding that the justification for social research ethics review on our account is based, not on ethics expertise but on a claim of legitimate authority that is derived from a process of fair consideration, we certainly do agree with Hammersley that members of ethics committees need to have access to appropriate knowledge of social research activities. For example, the committee needs to be satisfied that the relevant methodologies are being applied appropriately, and that the consent process is properly tailored to the methodological design of the study. Access to this 
knowledge is very important to the research ethics committee discharging its responsibilities correctly, but it is not of course correctly described as ethical expertise.

\section{References}

1. Hammersley M. A response to Sheehan et al's defence of pre-emptive ethics governance of social research. J Med Ethics 2018.

2. Sheehan M, Dunn M and Sahan K. In defence of governance: ethics review and social research. J Med Ethics 2018.

3. Hammersley M and Traianou A. Moralism and research ethics: A Machiavellian perspective. Int J Soc Res Meth 2011;14(5):379-390.

4. Hammersley M and Traianou A. Ethics in Qualitative Research: Controversies and Contexts. London: Sage 2012:57-74.

5. Dingwall R. The ethical case against ethical regulation in humanities and social science research. Twenty-First Century Society 2008;3(1):1-12. 